\title{
Battered granny or spontaneous fractures? A legal dilemma
}

\author{
V Connolly, AA McConnell, G McGarrity
}

\begin{abstract}
Summary
A 70-year-old woman was admitted from a local nursing home with extensive bruising and bilateral hip discomfort. The referring doctor had reported the possibility of elder abuse to the police. Full examination showed that osteomalacia, precipitated by a poor diet and lack of exposure to sunlight, was sufficient to explain the patient's condition. Caution is recommended in diagnosing elder abuse until other possibilities have been excluded.
\end{abstract}

Keywords: elder abuse, osteomalacia

Recent well-publicised cases have highlighted the dangers of health professionals making accusations which are later proved false, perhaps the best known of these are the cases arising in Cleveland and the Orkney Islands. These cases involved children, but there is potential for similar problems among the elderly population. Elder abuse has emerged as a major problem to which medical staff must be alert, ${ }^{1}$ indeed the American Medical Association have suggested that all older patients be asked about family violence. ${ }^{2}$ Failure to report genuine malicious injuries could also have serious repercussions. Diagnostic difficulties arise when medical conditions with similar clinical features coexist with abuse. We report a case where a diagnosis of elder abuse was made and reported to the authorities before an alternative explanation of the patient's presentation was discounted.

\section{Case report}

A 70-year-old Caucasian woman was admitted from a local nursing home, where she had been resident for three weeks, to a county hospital and subsequently transferred by boat to an orthopaedic centre. She presented with extensive bruising and bilateral hip discomfort. Her general condition was of such concern that the referring doctor had reported the possibility of criminal injury to the police.

Two weeks prior to this she had complained of hip pain, but radiographic investigations at that point did not demonstrate any fractures. There was no history of trauma from the patient or staff. She was quite immobile because of chronic rheumatoid arthritis of some 20 years duration which rendered her house- bound. Her vision was markedly impaired because of choroiditis. There were no features of steatorrhoea or malabsorption. Her diet was vegetarian supplemented with small amounts of milk, cheese and margarine. She never ventured outside and her main source of ligh was from sodium lamps, as she felt that fluorescent light further impaired her vision.

On examination she was conscious, alert, thin, pale and dehydrated with rheumatoid hands. There were huge haematomas around both hips with a further haematoma and tenderness in the right leg. Hypotension was noted at $96 / 50 \mathrm{mmHg}$ but no tachycardia nor features of cardiac failure. There were no abnormal neurological findings. Chvostek's and Trousseau's signs were negative.

The radiological findings were of bilateral comminuted fractures of the femoral neck with overriding of the fracture on the right side and varus angulation on the left with bilateral Losser's zones in the inferior pubic rami (figure 1). Radiographs of the right leg demonstrated fractures in the lower quarter of tibia and fibula, with healing fractures in the lateral tibial plateau and proximal tibial shaft (figure 2). An $\mathrm{X}$-ray of the chest displayed numerous bilateral rib fractures some of which exhibited callus formation.

The haemoglobin estimation was low at $6 \mathrm{~g} / \mathrm{dl}$. The biochemical results were as follows urea $23.5 \mathrm{mmol} / 1$, creatinine $178 \mu \mathrm{mol} / 1$, calcium $1.15 \mathrm{mmol} / 1$, albumin $34 \mathrm{~g} / 1$, phosphate $2.15 \mathrm{mmol} / \mathrm{l}$, alkaline phosphatase $735 \mathrm{IU} / 1$, magnesium $0.72 \mathrm{mmol} / 1,25$-hydroxy vitamin $\mathrm{D} 9 \mathrm{nmol} / 1$ and parathyroid hormone $9.2 \mathrm{pmol} /$ 1. Vitamin B12 and red blood cell folate values were within normal limits; after transfusion the haemoglobin remained within the normal range suggesting the anaemia was a result of blood loss associated with the fractures.

Initial treatment consisted of transfusion and intravenous fluid replacement; the serum creatinine fell to $92 \mu \mathrm{mol} / 1$ the next day. The fractures of femora were treated with bilateral Hamilton-Russell traction. Initially, surgical repair was avoided because of her poor general condition and hypocalcaemia, and later because of concern about bone fragility. Vitamin D supplements were provided using vitamin $\mathrm{D} /$ calcium tablets containing 500 IU of vitamin D and $2.4 \mathrm{mmol}$ of calcium. Appropriate dietary therapy was instituted. Serum calcium rose to $2.25 \mathrm{mmol} / 1$ within three weeks.

As a result of the initial contact with the police by the referring doctor, an inquiry was 


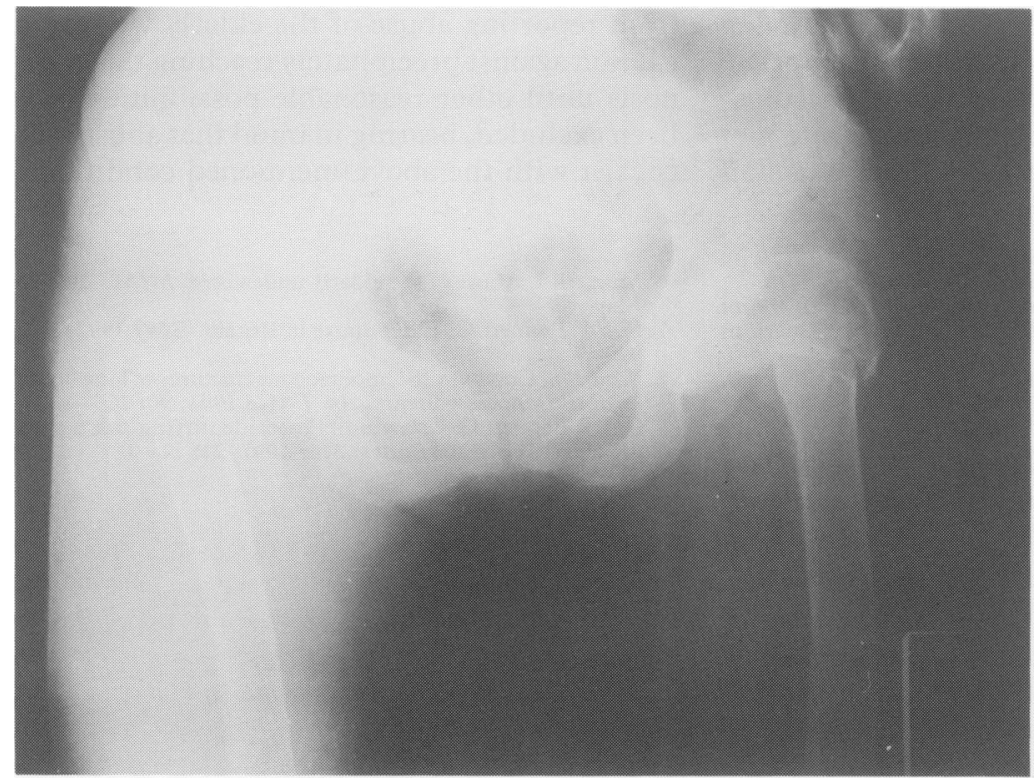

Figure 1 Bilateral comminuted fracture of femora with varus angulation

Table Risk factors in the abused and abuser which predispose to abuse of the elderly

\begin{tabular}{ll}
\hline Abused & Abuser \\
\hline Aggressive/disruptive behaviour & History of psychological illness \\
Poor health & Alcohol/drug abuse \\
Social isolation & Financial dependence on abused \\
Living with carer & Recent lifestyle change \\
& Male relative \\
\hline
\end{tabular}

Adapted from references $8 \& 9$.

received from the local police regarding the possibility that the injuries were of a criminal nature. A very neutral and guarded response was given to this inquiry pending clinical investigation. Functionally her hips improved remarkably with the result that two months after admission she was able to take 60 steps.

\section{Comment}

The reported prevalence of elder abuse ranges from $5-65 \%$, depending on the criteria by which the condition is defined. ${ }^{3}$ While the term 'granny battering' clearly implies physical abuse, elder abuse has a broader scope including emotional, financial and social abuses. In addition, neglect or inadequate care also constitute abuse. These points and an approach to abuse have been recently reviewed. ${ }^{4}$

In our patient several features were suggestive of abuse: recent extensive bruising and fractures which, at the time of presentation, were unexplained, a chronic illness, a selfwilled personality, immobility and nursing home residence. ${ }^{5,6}$ Denials of abuse from the abused or the carer would not necessarily preclude the diagnosis. ${ }^{7}$ However, there is no doubt from the radiological and biochemical findings that, in this situation, osteomalacia, precipitated by a poor diet and lack of exposure to sunlight, was sufficient to explain the injuries incurred. This explanation clearly did not rule

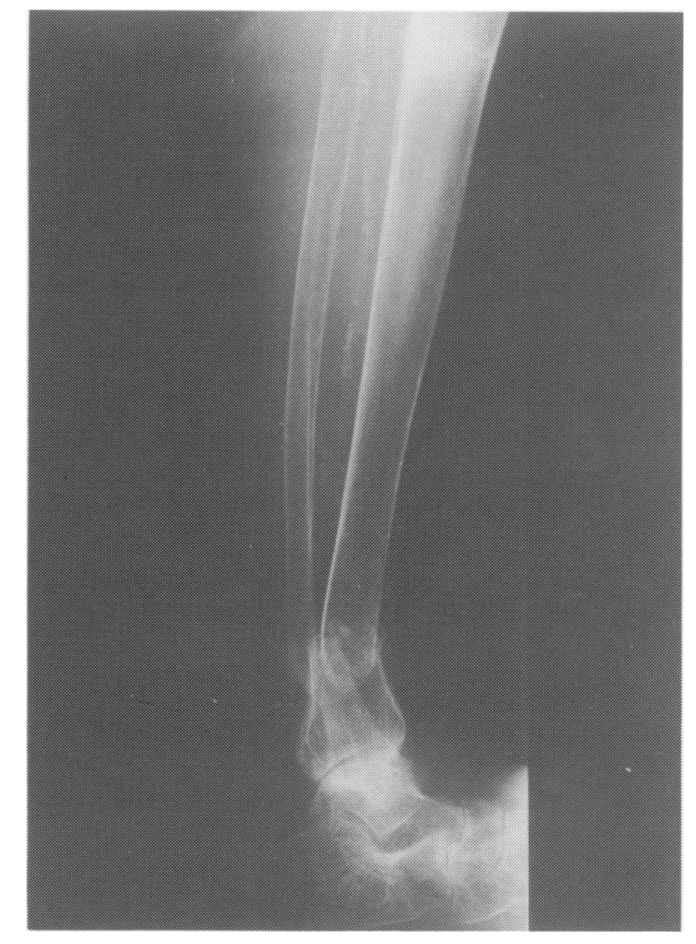

Figure 2 Fractured tibia and fibula with healing fractures in the lateral tibial plateau

out abuse as an additional factor. There are literature reports of spontaneous long bone fractures in chronically immobile patients that have also been reported as abuse of the elderly ${ }^{8}$ but not involving osteomalacia.

While no evidence of physical abuse was uncovered by the police and social services, the development of severe osteomalacia in a nursing home patient may be considered inadequate care.

Similar problems may also arise in the context of children with osteogenesis imperfecta who present with fractures, or bruising in patients with idiopathic thrombocytopenic purpura. Careful assessment is important and the presence of these conditions will not preclude deliberate physical injury.

False accusations can be very costly for the accuser leading to legal action for defamation, damages for lost profits and loss of earnings, which in the context of a nursing home could be substantial. Most accusations would be covered by qualified privilege, which means that the pursuer/plaintiff would have to show the accuser was motivated by malice.

\section{Learning points}

- abuse of the elderly can coexist with other conditions

- abuse of the elderly should be considered when fractures are present

- neglect or inadequate care are considered to be forms of abuse

- risk factors for abuse have been identified 
Removal of the patient from the nursing home to hospital allows time for appropriate investigation and clarification of the circumstances which aroused suspicion. While not wishing to dissuade medical and nursing staff

1 Pitt B. Abusing old people. BMf 1992; 305: 968-9.

2 American Medical Association. Diagnostic and treatment guidelines on elder abuse and neglect. Chicago: American Medical Association, 1992.

3 Fisk J. Abuse of the elderly. In: Jacoby R, Oppenheimer C, eds. Psychiatry in the elderly. Oxford: Oxford University Press, 1991.

4 Lachs MS, Pillemer K. Abuse and neglect of elderly persons. $N$ Engl f Med 1995; 332: 437-43.

5 Rounds L. Elder abuse and neglect: a relationship to health characteristics. $\mathcal{F}$ Am Acad Nurse Pract 1992; Apr-Jun: from reporting abuse of the elderly we would caution against precipitately reaching this diagnosis until other reasonable possibilities have been excluded, bearing in mind that abuse may coexist with the above-mentioned conditions.

6 Mundell I. Abuse of the elderly undetected. MIMS 1992; 6 May

7 Ogg J, Bennett G. Elder abuse in Britain. BMF 1992; 305: 998-9.

8 Kane RS, Goodwin JS. Spontaneous fractures of long bones in nursing home patients. Am f Med 1991; 90: 263-6.

Ogg J, Bennett G. Community care: identifying risk factors for elderly abuse. Geriatric Med 1991; 21: 11-9.

\title{
Spontaneous regression of pulmonary mucormycosis
}

\author{
Prakash Abraham, Shalini Govil, Vivi M Srivastava, Alka Ganesh
}

\section{Summary \\ A case of pulmonary mucormycosis with spontaneous resolution is presented. The patient had no known underlying predis- posing disease.}

Keywords: pulmonary mucormycosis, Graves thyrotoxicosis

Mucormycosis is usually a fulminant infection with a high mortality unless treated aggressively with amphotericin and surgical debridement. It occurs primarily in patients who have diabetes mellitus and immunocompromised states. We report an unusual case of pulmonary mucormycosis which regressed spontaneously without antifungal or surgical treatment. Also unusual was the fact that the patient did not have any described underlying predisposing cause for developing the infection. He had Graves thyrotoxicosis, which has not so far been described in association with mucormycosis.

Christian Medical College \& Hospital, Vellore, India Department of Medicine

P Abraham A Ganesh

Department of

Radiodiagnosis S Govil

Department of

Pathology

VM Srivastava

Correspondence to Dr Alka Ganesh, Department of Medicine III, Christian Medical College \& Hospital, Vellore 632004, Tamil Nadu, India

Accepted 26 April 1995

\section{Case report}

A 50-year-old man from North Eastern India, who had been suffering from thyrotoxicosis and chronic diarrhoea intermittently for 12 years, presented with jaundice, worsening diarrhoea dehydration and altered sensorium, for three weeks. He had abused alcohol in the past, but had abstained for the last five years. He had no respiratory symptoms. Examination revealed a dehydrated, icteric, emaciated man. The liver was palpable $2 \mathrm{~cm}$ below the costal margin. Splenomegaly, ascites, and signs of liver cell failure were absent. The thyroid gland was diffusely enlarged. The blood pressure was $100 / 70 \mathrm{mmHg}$ and pulse was 88 beats $/ \mathrm{min}$.
The respiratory and cardiovascular systems were normal.

The results of pertinent laboratory investigations are given in the box. Serum potassium, calcium, phosphorus and bicarbonate values were normal. Hepatitis B surface antigen and antibodies to HIV were negative. Stool microscopy, culture and fat content were normal Sputum was negative for acid-fast bacilli and fungus.

Chest X-ray showed two nodular opacities in the midzones with cavitation, the largest measuring $4 \mathrm{~cm}$ (figure 1). Computed tomography (CT) revealed a $3-\mathrm{cm}$ soft tissue density nodule in the lingula, with no evidence of cavitation or calcification. A similar 1-cm lesion was also seen in the middle lobe (figure 2).

The patient's renal function and general condition improved rapidly with hydration. Neomercazole was thought to contribute to hepatic derangement, and after its withdrawal

\section{Laboratory results}

haemoglobin (g/dl)

total white cells $\left(\times 10^{9} / 1\right)$

neutrophils (\%)

blood urea (mmol/l)

serum creatinine $(\mu \mathrm{mol} / \mathrm{l})$

serum sodium ( $\mathrm{mmol} / \mathrm{l})$

total bilirubin $(\mu \mathrm{mol} / 1)$

direct bilirubin $(\mu \mathrm{mol} / 1)$

total protein $(\mathrm{g} / \mathrm{l})$

serum albumin $(\mathrm{g} / \mathrm{l})$

serum aspartate transaminase (IU/l)

serum alanine transaminase (IU/l)

serum alkaline phosphatase (IU/1)

random blood sugar ( $\mathrm{mmol} / \mathrm{l})$

total thyroxine ( $\mathrm{nmol} / \mathrm{l})$

free thyroxine (pmol/1) 